\title{
CULTURA DE VIDRO: O EMPOBRECIMENTO DA ARTE NA PERSPECTIVA DE WALTER BENJAMIM E THEODOR W. ADORNO
}

Lia Freitas Oliveira ${ }^{1}$

\begin{abstract}
RESUMO
O diálogo entre Adorno e Benjamin a respeito do impacto da lógica capitalista na experiência do homem moderno é intenso e perpassado de perspectivas que se convergem, mas que cindem em um determinado momento. Segundo Benjamin, a natureza fragmentária da realidade, condicionada à aceleração do mercado, interfere na memória, empobrecendo a capacidade de intercambiar experiências e de narrá-las. Adorno percebe que essa pobreza de experiência degenera a arte, que é utilizada como forma de dominação cultural, responsável por introduzir uma padronização estereotipada. A cultura de vidro é uma resposta à frieza das relações humanas e ao embotamento da consciência. Apesar das semelhanças ambos os filósofos se auto-apresentam sob perspectivas alheias, justificando a teoria das diferenças que cada um defende. No desfecho dessa reflexão, caminhos diferentes são tomados para pensar sobre o valor que a arte tem nessa cultura empobrecida e que potencial político ela ainda guarda diante dessa esterilizada cultura de vidro.
\end{abstract}

Palavras-chave: Experiência. Indústria Cultural. Cultura de Vidro. Arte.

\section{GLASS CULTURE: THE IMPOVERISHMENT OF ART BY THE PERSPECTIVE OF WALTER BENJAMIN AND THEODOR W. ADORNO}

\section{ABSTRACT}

The dialogue between Adorno and Benjamin about the impact of the capitalist logic in modern man experience is intense and permeated by converging perspectives, that diverge in a determined moment. According to Benjamin, reality's fragmentary nature, conditioned by market's acceleration, interferes in memory, impoverishing the capability to exchange experiences and narrate them. Adorno perceives that this poverty of experience degenerates the art, that is used as a manner of cultural domination, responsible of introducing a stereotyped pattern. The glass culture is a response to the coldness of human relations and the dullness of conscience. Inspite of the similarities both philosophers self-introduce themselves under distinct perspectives, justifying the theory of differences each one defends. At the end of this reflection, different paths are taken to think the value that art has in this impovered culture and what political potential it still keeps in front of the sterilized glass culture.

Key-words: Experience. Cultural Industry. Glass Culture. Art.

\footnotetext{
${ }^{1}$ Lia Freitas Oliveira é graduanda do Curso de Filosofia da Universidade Estadual do Ceará (UECE).
} 
No ensaio Experiência e Pobreza de 1933, Walter Benjamin traz uma reflexão a respeito da "miséria" da cultura moderna, transformada em barbárie. Pensar nessa experiência pobre da modernidade é remeter a um novo tipo de experiência, que precisa ser assumida para se poder "começar de novo". Para ele esse novo modo da cultura chega ao homem através da economia de mercado e das experiências funestas da Primeira Grande Guerra, que esvaziaram os homens de sua própria experiência, suas memórias. Theodor $\mathrm{W}$. Adorno também remete à questão da cultura ressequida pelos valores do capital em seu texto Indústria Cultural: $O$ Esclarecimento como Mistificação das Massas. Neste texto, Adorno apresenta como a cultura foi engolida pela lógica capitalista e transformada em mercadoria, e o quanto a arte foi usada como instrumento de mistificação das massas. A arte, antes produção espiritual, expressão humana, degenera-se em mercadoria cultural.

Este artigo tem a intenção de trazer à tona o que de igual e de diferente repousam sobre o pensamento dos dois filósofos frankfurtianos a respeito da cultura e principalmente da arte, levando em conta o diálogo entre suas ideias e os contrapontos que surgem ao longo da caminhada desses dois teóricos. Adorno e Benjamin pensaram sobre os impactos e as mudanças que a produção artística sofreu ao longo dos séculos pela transformação política e econômica do mundo ocidental com a ascensão do complexo capitalista burguês.

A proposta é refletir o que a arte sofreu - e ainda sofre - com a pobreza de experiência do homem moderno e o consequente empobrecimento da cultura. Qual o valor que a arte tem nessa cultura empobrecida? Pergunta-se Benjamin. Já Adorno, diante da dominação como status quo da Modernidade, pergunta-se também em sua Teoria Estética: "o que seria a arte enquanto historiografia, se ela se desembaraçasse da memória do sofrimento acumulado?"2

\section{Experiência e Pobreza}

Esse parágrafo começa com a inquietante pergunta: "Pois qual o valor de todo o nosso patrimônio cultural se a experiência não mais o vincula a nós? ? $^{3}$. Walter Benjamin se questiona sobre um novo panorama que se estabeleceu na vida dos

2 Theodor W. Teoria Estética. Tradução: Artur Mourão. Lisboa: Edições 70, 2008, p. 96.

3 BENJAMIN, "Experiência e Pobreza" in: Magia e Técnica, Arte e Política - Obras Escolhidas I, Tradução de: Sergio Paulo Rouanet. São Paulo: Brasiliense, 2010, p. 115. 
homens no início do século XX. A Primeira Guerra Mundial veio para mutilar o fio de experiências que o capital já há muito vinha pungindo. $O$ homem da modernidade é um bárbaro, é um individuo clivado de sua experiência.

Para compreender melhor o que significa em Benjamin o conceito de experiência, é preciso voltar ao texto $O$ Narrador. Considerações sobre a obra de Nikolai Leskov, de 1936. Benjamin vincula o conceito de experiência à memória e ao arsenal de conhecimentos para a vida. A narração contém essa experiência, hoje em dia perdida. A narração está vinculada a um saber que não é posse, e sim compartilhado na oralidade pelo homem do campo, ou pela figura do forasteiro ou marinheiro, pronto a narrar suas aventuras. Ela vem das memórias da vida desse homem, histórias que são repassadas com a finalidade de não somente intercambiar essas experiências, mas de trazer lições para quem as ouve. A sabedoria é a tônica dessas histórias, carregadas de conselhos e valores morais. Com o enfraquecimento da memória, "a arte de narrar está definhando porque a sabedoria - o lado épico da verdade - está em extinção"4. A narração é prática, as histórias do narrador foram vivenciadas na realidade, não são lições retóricas. Elas trazem ensinamentos, pois a história de um narrador não é somente para se jogar ao vento, ou ser esquecida por quem a ouve, mas para que se possa tirar dela orientações para a vida. Esses ensinamentos são tecidos na memória que os avalia e acrescenta. Por isso diz Benjamin que "a memória é a mais épica de todas as faculdades". Muitas vezes o que é rememorado traz a melancolia, às vezes o tédio. Mas não se trata de uma melancolia negativa, pelo contrário, Benjamin relaciona o dom de ouvir ao trabalho artesanal, feito espontaneamente, construído com paciência e reflexão:

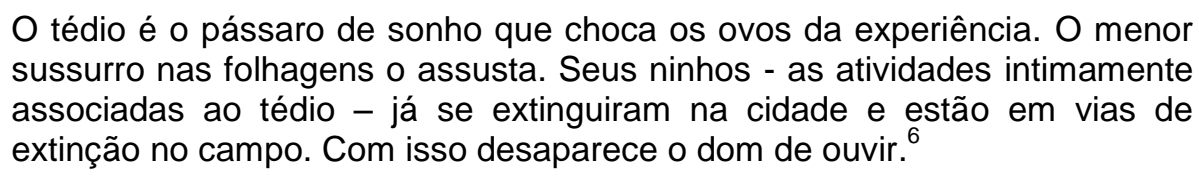

A perda da capacidade narrativa dá lugar à nova forma de comunicação que surge com a era da burguesia: a informação ${ }^{7}$. Esta se instaura com a criação da imprensa e se adéqua muito mais ao novo padrão cultural da economia burguesa.

\footnotetext{
${ }^{4}$ BENJAMIN. "O Narrador. Considerações sobre a obra de Nikolai Leskov" in: Magia e Técnica, Arte e Política - Obras Escolhidas I, São Paulo: Brasiliense, 2010, p.200-201.

5 Idem, ibidem, p. 210.

6 Id. Ibid., p. 204-205.

Id. Ibid.,p. 202.
} 
A informação só tem valor no momento em que é nova. Ela só vive nesse momento, precisa entregar-se inteiramente a ele e sem perda de tempo tem que se explicar nele. Muito diferente é a narrativa. Ela não se entrega.

Enquanto a informação aspira a uma verificação imediata ${ }^{9} 0$ tempo da narrativa é mais lento, pois é preciso ruminar (Grübeln), refletir sobre os fatos narrados. Isso é o que dá espaço para a interpretação. É nesse ponto que ela é compreendida como uma atividade que causa tédio. Mas a narração libera os indivíduos, tanto o que conta quanto o que ouve, para imaginar, interpretar de diversas formas. Nela, o ouvinte tem um importante papel como transmissor da sabedoria acumulada. A informação não se preocupa com isso. Ela compactua com a aceleração da vida moderna, pois só deseja comunicar o fato, o que acontece imediatamente, o mais rápido possível. Ela preza pela imparcialidade e se fixa na realidade, despreza o conteúdo anímico. A informação está interessada em transmitir o "puro em si" da coisa.

A exigência do novo na informação combate a ideia mnemônica da narrativa. Aqui entra, mais uma vez, o problema do empobrecimento da experiência, outrora regida pela sabedoria ao longo dos tempos. O homem moderno é um indivíduo sem experiência porque a própria cultura se desvinculou da memória, dos valores duráveis, passados de geração em geração. O novo é o que rege a economia capitalista, a mercadoria e por fim a cultura. Para Benjamin esse novo é enganoso, é o que empobrece. Ele compactua com o sempre igual (das Immer-gleiche) do mercado, gerando a competição entre os homens. Com a divisão do trabalho e a aceleração do processo de fabricação (Herrstellungsverfahren), as grandes mudanças políticas e econômicas chegaram até a cultura impondo outro tipo de relação entre os homens: a dominação. Mas apesar da exacerbação do valor de troca, o empobrecimento da experiência não tem somente um viés negativo. Benjamin vê uma potencialidade de resistência nesse esvaziamento.

Adorno também aborda a questão do esvaziamento da cultura pelo sistema capitalista burguês. O autor toma a questão da cultura como mercadoria. Seu esvaziamento se dá por conta do caráter descartável que ela ganha no sistema do capital.

\footnotetext{
8 Id. Ibid., p. 204.

Idem.
} 
A cultura é uma mercadoria paradoxal. Ela está tão completamente submetida à lei da troca que não é mais trocada. Ela se confunde tão cegamente com o uso que não se pode mais usá-la. É por isso que ela se funde com a publicidade. Quanto mais destituída de sentido esta parece ser no regime do monopólio, mais toda poderosa ela se torna (...). A publicidade é seu elixir da vida. Mas como seu produto reduz incessantemente o prazer que promete como mercadoria a uma simples promessa, ele acaba por coincidir com a publicidade de que precisa, por ser intragável. ${ }^{10}$

O conceito de indústria cultural introduz essa questão, mostrando o quanto a dominação praticada ela é responsável por inculcar a padronização estereotipada, a fim de legitimar a ideologia do todo econômico-social. Nesse contexto a racionalidade instrumental é o que rege o pensamento. A arte é utilizada como instrumento de dominação cultural. A reprodutibilidade e a massificação da mercadoria artística têm como fim dissolver as individualidades na massa. O cinema, o sucesso radiofônico, tudo é feito para padronizar os desejos. "(...) é só porque os indivíduos não são mais indivíduos, mas sim meras encruzilhadas da tendência do universal, que é possível reintegrá-los ( $\mathrm{sic}$ ) totalmente ao universal"11.

A indústria cultural é produz o entretenimento. A familiaridade dos conteúdos dos produtos culturais é responsável pelo adestramento das mentes narcotizadas pelas mercadorias descartáveis. Adorno dará a esse contexto o nome de Verblendungszusammenhan ${ }^{12}$, ou seja, é o contexto geral de ofuscamento, onde a fantasmagoria da metrópole hipnotiza de tal forma a vontade a ponto de interferir na decisão. Assim todos são movidos pela propaganda. O processo de dominação não poupa nem o tempo de lazer. A shortstory domestica a mente, limitando seu potencial ao facilmente digerível, palatável. É na distração que a dominação aparece. A falsa diferenciação entre os produtos fabricados em série produz no sujeito o idílio da possibilidade de escolha. A uniformização e a falsa ideia de possibilidades ilimitadas empobrecem o material estético da obra de arte. Essa possibilidade está na ideia do novo.

No processo de dominação da sociedade totalmente administrada

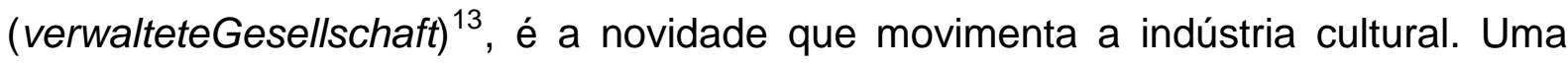
falsa novidade, já que tudo se adéqua ao padrão mercadológico. O fetiche do novo

\footnotetext{
${ }^{10}$ ADORNO, Theodor W. HORKHEIMER, Max. Dialética do Esclarecimento. Tradução: Guido Antonio de Almeida. Rio de Janeiro: Zahar, 2006, p. 134.

${ }^{11}$ ADORNO, Theodor W. HORKHEIMER, Max. Dialética do Esclarecimento. Tradução: Guido Antonio de Almeida. Rio de Janeiro: Zahar, 2006, p. 128.

12 "Contexto geral de ofuscamento". ADORNO, Theodor W. Palavras e Sinais - modelos críticos 2 Tradução de Maria Helena Ruschel, Petrópolis: Vozes, 1995, p. 241.

${ }^{13}$ Id. Ibid., p. 239
} 
se adere à mercadoria cultural. Os enredos clichês dos filmes são disfarçados pela precisão dos detalhes técnicos, e isso é o que produz a sedução, o que induz o desejo do consumidor. A cada sucesso, é obrigatória a presença da novidade,o que traz a falsa ideia de diferenciação.

Benjamin, anos antes, reflete sobre a questão da reprodutibilidade técnica na arte. Adorno produziu o capítulo sobre a indústria cultural muito influenciado pelas ideias que Benjamin introduziu no seu texto $A$ obra de arte na era de sua reprodutibilidade técnica ${ }^{14}$. Tanto é que se percebe o intenso diálogo entre as ideias de ambos os textos. No ensaio Experiência e Pobreza, Benjamin fala sobre um sintoma da modernidade que se desenvolve no texto $A$ obra de arte na era de sua reprodutibilidade técnica, a ponto de interferir no princípio que a gera - a criação. Nesse ultimo texto, o autor discorre sobre a situação da obra-de-arte reproduzida na modernidade, principalmente na criação e no desenvolvimento da fotografia, que desemboca no surgimento do cinema.

Benjamin aponta as mudanças que ocorreram ao longo dos séculos na produção artística e na sua recepção, mostrando as diferenças histórico-culturais entre a contemporaneidade e a antiguidade. Procura-se pensar, nesse contexto qual a relação entre a pobreza de experiência e a arte reproduzida, traçando um paralelo também com os questionamentos adornianos a respeito da crítica à indústria cultural e a degeneração da obra de arte.

\section{Cultura de Vidro e a perda da memória: empobrecimento da arte}

Pra pensar o que poderia produzir o empobrecimento da experiência humana a ponto de desvincular a própria cultura, produto humano, do homem, a alusão ao vidro, usada por Benjamin, é bastante ilustradora.

No texto Experiência e Pobreza, o autor faz referência ao escritor Paul Scheerbart e sua literatura fantástica, futurista. Benjamin introduz a figura do escritor alemão para mostrar a tendência avant garde do espírito moderno, na tentativa de tirar algo de novo e potencialmente inovador da pobreza que se instaurou na cultura. Homens como Scheerbart buscam algo de revolucionário nessa experiência: "sua característica é uma desilusão radical com o século e ao mesmo tempo uma total

$141935 / 1936$ 
fidelidade a esse século"15. A desilusão vem da extrema miséria que a experiência da cultura mercantil burguesa trouxe à humanidade, mas, ao mesmo tempo, é dessa desilusão que surge a coragem para transpor e trazer à tona o "novo, o revolucionário". Ora, mas é pretensamente do novo que a cultura capitalista se nutre. Aliás, a modernidade pressupõe o novo. Então, Benjamin vê uma potencialidade criadora nessa cultura bárbara que se estabeleceu - o desafio para um recomeço ${ }^{16}$. Dessa forma apresenta a figura do vidro, usada na literatura de Sheerbart, para trazer a perspectiva de uma cultura moderna, avançada, mas também para realçar sua ambivalência:

Mas, para voltarmos a Scheerbart: ele atribui a maior importância a tarefa de hospedar sua 'gente', e os concidadãos, modelados à sua imagem, em acomodações adequadas a sua acomodação social, em casas de vidro, ajustáveis e móveis, tais como as construídas, no meio tempo, por Loos e Le Corbusier. ${ }^{17}$

Assim, o vidro aparece com a imagem de um material tipicamente moderno. Ele é prático, de fácil modelagem, leve, e de design avançado. A produção de objetos feitos de vidro é mais rentável que os de madeira, por exemplo. Enfim, o vidro é o material progressista. No entanto, Benjamin afirma:

Não é por acaso que o vidro é um material tão duro e tão liso, no qual nada se fixa. É também um material frio e sóbrio. As coisas de vidro não tem nenhuma aura. $\bigcirc$ vidro é em geral inimigo do mistério. É também o inimigo da propriedade. ${ }^{18}$

O vidro apaga os rastros, pois nada se fixa, configurando-se como um material sem memória. Por isso, ele não tem aura. Sua aparência padroniza, retira dos objetos suas peculiaridades. O que vemos então é que a cultura do vidro se estabelece na sociedade burguesa, não somente nos objetos, mas transforma 0 comportamento do homem, sempre sob a vigilância de alguém. Funciona como um panopticon ${ }^{19}$. Por ser transparente, ou translúcido, dá uma falsa impressão de

\footnotetext{
${ }^{15}$ BENJAMIN, Walter. "Experiência e Pobreza" in: Magia e Técnica, Arte e Política Obras Escolhidas I.Tradução: Sergio Paulo Rouanet. São Paulo: Brasiliense, 2010, p. 116. .

16 "Barbárie? Sim. Respondemos afirmativamente para introduzir um conceito novo e positivo de barbárie. Pois o que resulta para o bárbaro dessa pobreza de experiência? Ela o impele a partir para a frente, a começar de novo, a contentar-se com pouco, a construir com pouco, sem olhar nem para a direita nem para a esquerda. Entre os grande criadores sempre existiram homens implacáveis que operaram a partir de uma tábula rasa" ld. Ibid., p. 115-116.

${ }^{17}$ Id. Ibid., p. 117.

${ }^{18}$ Idem.

${ }^{19} \mathrm{O}$ vidro e o panopticon se assemelham quanto à propriedade da vigilância que ambos sugerem. Por isso é possível a comparação desse material com a construção de uma prisão arquitetada por
} 
comunicação com o que está por detrás. O vidro separa ao mesmo tempo em que revela. Podemos pensar então que esse homem pobre, desvinculado de sua cultura, é um homem enjaulado na cela de vidro da própria cultura. "Em seus edifícios, quadros, e narrativas, a humanidade se prepara, se necessário, para sobreviver à cultura" (grifo nosso) ${ }^{20}$.

Esse desvincular da cultura da vida humana é um sintoma típico da sociedade capitalista. A fragmentação da vida gera esse estado. A arte irá sofrer, assim como todos os outros setores da cultura, desse mesmo mal ${ }^{21}$. A partir disso, começamos a pensar sobre se ela pode manter seu valor e importância desvinculados do homem, uma vez aderida à lógica mercantil. Será que a arte consegue manter-se afastada dessas relações? E quais as potencialidades de resistência que podemos encontrar na arte, mesmo inserida nesse contexto?

Com a perda dos valores que norteavam o homem para uma transmissão de saberes de que fala o ensaio "O Narrador", a modernidade trouxe consigo o total aniquilamento do modelo de comunidade na tradição. Esse aniquilamento foi transferido para a manifestação artística. A dissolução dos gêneros de que fala Adorno em Teoria Estética é uma expressão do descrédito em um "gênero puro"22, Benjamin por sua vez compreende a subtração dos gêneros tragédia e comédia para dar espaço a uma miscelânea, onde uma compartilha a arte com a outra. Assim valoriza o princípio estético que orienta a dramaturgia barroca alemã, como expressão da força do presente: "A tragédia antiga é uma escrava acorrentada ao carro triunfal do barroco"23. Os dois grandes teorizadores da arte na Modernidade concordam com relação ao pensamento de Croce e sua crítica ao nominalismo estético, quanto à dissolução das células estanques que acondicionavam os gêneros: para Benjamin "uma obra de arte significativa ou funda um gênero ou o

Jeremy Bentham comentada por FOUCAULT, Microfísica do Poder, Tradução: Roberto Machado, Rio de Janeiro: Edições Graal, 1979, p. 210.

${ }^{20}$ BENJAMIN, Walter"Experiência e Pobreza" in: Magia e Técnica Arte e Política Obras Escolhidas I, Tradução: Sergio Paulo Rouanet. São Paulo: Brasiliense, 2010, p. 119.

${ }^{21}$ Essa ausência de vínculo se expressa no movimento L'artpourl'art, repudiado por ambos os filósofos.

22 "O que aconteceu às categorias do trágico e do cômico atesta o declínio dos gêneros estéticos enquanto gêneros.A arte está inserida no processo global do nominalismo em avanço, desde que se estilhaçou a ordo medieval. Mas nenhum universal the foi concedido..." ADORNO, Theodor W. Teoria Estética. Tradução: Artur Mourão. Lisboa: Edições 70, 2008, p. 302.

${ }^{23}$ BENJAMIN,Walter. Origem do Drama Barroco Alemão. Tradução: Sergio Paulo Rouanet,São Paulo, Editora Brasiliense, 1984, p. 122. 
transcende, e numa obra de arte perfeita as duas coisas se fundem numa só"24. Percebe-se então que a Modernidade, apesar da degeneração da cultura em barbárie e da fragmentação da vida, introduz uma alternativa positiva de superação. Com a perda das concepções divinatórias, o pensamento moderno traz a possibilidade de abandonar o encaixotamento de um gênero verdadeiro, ou de uma adequação da obra em parâmetros estilísticos, para explorar pluralidade do homem moderno.

Adorno também retoma essa questão, pensando a respeito da análise imanente das obras de arte, pois não se pode tomá-las a partir de um gênero, isto é, partir de um universal, para em seguida analisá-la. Pelo contrário, é preciso partir da própria obra, do que ela tem a dizer sobre seu tempo, e até que ponto ela consegue ultrapassar os modelos desse tempo. Segundo o autor:

A experiência de crítica de arte de Croce segundo a qual toda a obra deve,
segundo a expressão inglesa, ser julgada on its ownmerits, trouxe essa
tendência histórica para a estética teórica. Sem dúvida nunca uma obra de
arte de importância correspondeu inteiramente ao seu gênero. ${ }^{25}$

Ainda assim, a cultura fetichista burguesa reproduz freneticamente o idílio da novidade. A arte adere, assim como todas as coisas, a esse fetiche mercadológico, tornando-se mais um instrumento inofensivo de reprodução da ratio capitalista, da razão instrumentalizada. Adorno faz referência a essa situação em sua crítica à indústria cultural e deixa claro o processo de degeneração da arte diante da submissão pela qual ela tem de passar para se afirmar na sociedade. Benjamin também vai pensar sobre a dificuldade do conteúdo da obra de arte a serviço do capital. Segundo ele:

Não se deve, evidentemente, esquecer que a utilização política desse controle terá que esperar até que o cinema se liberte de sua exploração pelo capitalismo. Pois o capital cinematográfico dá um caráter contra revolucionário às oportunidades revolucionárias imanentes a esse controle. ${ }^{26}$

Ambos refletem a respeito da degeneração da cultura e acreditam numa possibilidade de salvação da arte, aproveitando os elementos que a empobrece, para através deles, criar grandiosamente. Mas, apesar das identificações que se

\footnotetext{
${ }^{24}$ Id. Ibid., p. 66.

${ }^{25}$ ADORNO, Theodor W. Teoria Estética. Tradução: Artur Mourão. Lisboa: Edições 70, 2008, p. 302.

${ }^{26}$ BENJAMIM, Walter. "A Obra de Arte na Era de sua Reprodutibilidade Técnica" in: Magia e Técnica Arte e Política Obras Escolhidas I. Tradução: Sergio Paulo Rouanet. São Paulo: Brasiliense, 2010, p. 180.
} 
pode encontrar, é importante acentuar as diferenças de pensamento dos dois filósofos frankfurtianos.

\section{Adorno e Benjamin: embates}

O problema que se coloca a respeito dessa perda de valor da arte é que autonomia ela tem a partir do momento em que se torna instrumento. Que tipo de presença ela tem e ela quer ter diante do abrandamento de suas forças. Ou seja, que valor político ela tem em sua expressão se ela mesma está vazia de qualquer pensamento autônomo crítico, quando ela se submete às ideologias socialmente impostas. As perspectivas de Benjamim e Adorno no tocante ao enfraquecimento da arte na estrutura social bifurcam-se num dado momento em que desenvolvem suas reflexões. Como já foi dito antes, ambos concordam com a dificuldade da arte perante a dominação, ao jugo do sistema e ao ônus amargo que ela paga por ter se vendido a ele. Mas, quanto à potencialidade crítica e politicamente renovadora da arte diante desse contexto, os dois teóricos introduzem diferentes perspectivas de possibilidades.

Adorno pensa que a arte inserida no contexto da reprodutibilidade mercadológica, mais especificamente, como instrumento da indústria cultural, perde totalmente o corte. Seu potencial crítico e político é completamente comprometido e abrandado. O que proporciona isso é o caráter de entretenimento que a indústria cultural legou à arte. A arte serve - nota-se assim o valor utilitarista que ela recebe para distração, para o lazer do trabalhador. Por isso as mercadorias culturais precisam ser leves, de fácil acesso, com conteúdos rapidamente identificáveis e digeríveis. Pois, um trabalhador, de vida dura e que sofre uma rotina desgastante, não pode encontrar na sua frente mais um obstáculo, um enigma que constranja seu entendimento, no seu cotidiano. Na realidade, a tentativa da indústria cultural é de acomodar o indivíduo em sua condição social, pois dando a ele conteúdos leves e descartáveis, este continuará a reproduzir a lógica que o consome.Adorno afirma:

Divertir-se significa estar de acordo. (...) Divertir-se significa sempre: não ter que pensar nisso, esquecer o sofrimento até mesmo onde ele é mostrado. A impotência é sua própria base. É na verdade uma fuga, mas não, como afirma, uma fuga da realidade ruim, mas da última idéia de resistência que essa realidade ainda deixa subsistir. ${ }^{27}$

\footnotetext{
${ }^{27}$ ADORNO, Theodor W. HORKHEIMER, Max. Dialética do Esclarecimento.Tradução: Guido Antonio de Almeida. Rio de Janeiro: Zahar, 2006, p. 119.
} 
Para Adorno a indústria cultural fere a obra de arte de forma nevrálgica ao corromper sua expressividade. Os conteúdos programados, a tentativa técnica de identificação perfeita com a realidade, os clichês moldados para a fácil percepção e compreensão do consumidor matam aquilo que de crítico a obra possui: sua aparência estranha. Adorno compreende que a obra de arte para se fazer autônoma precisa expressar a crítica em sua forma, não em seu conteúdo. É pela aparência estranha de um quadro, por exemplo, que o inconformismo surge. A obra de arte é representação da realidade, mas não deve se prender à cópia fiel dela, pois é pelo estranhamento da expressão artística que o indivíduo se abala.

É na construção mimética que há o afastamento do elemento real para o contexto da obra de arte. Nesse distanciamento se constrói a expressão estética da obra. A arte sempre pretende ser aquilo que ela não é, ou seja, o objeto representado, por esse motivo é tão tenso seu processo. Integrar duas realidades sem subjugar uma à outra não é uma tarefa simples. $O$ fato e a aparência misturamse sem violentar a essência de ambos. Não há uma imposição, mas há uma forte tensão no fato de serem opostos integrando-se.

É sempre um jogo entre realidade e ilusão, jogando em uma dinâmica dialética. Assim a arte não deseja ser uma imagem da coisa, mas a própria. $O$ imediato de sua aparição, o instante hermético de sua aparência distanciada desdobra-se em sua verdade: o enigma da sua verdade intrigante. A verdade da sua aparência se desvela na sua possibilidade de não ser seu próprio pressuposto. $O$ caráter de aparência da sua verdade é quem revela sua ilusão e ao mesmo tempo quem possibilita suas inúmeras experiências e interpretações. $O$ abalo que essa experiência causa é o desvelar do seu conteúdo de verdade: a crítica à realidade social. Sendo assim, a obra que se propõe a desenvolver a expressão como uma construção concisa e autêntica é sempre uma obra com um compromisso político por criticar a homogeneidade e totalização da realidade social. Por isso ela tem de se afastar dessa realidade mercadológica padronizadora dos conteúdos para retornar ao real pela crítica. A arte que tem potencial político de resistência é, sobretudo, aquela que incomoda e não a que aplaina as emoções e pensamentos.

Já em Benjamin o potencial crítico da obra se encontra numa nova percepção que surge com a reprodutibilidade: a distração. O hábito é o que rege a experiência estética das massas. A obra de arte se adéqua a esse novo modo de vida moderno: 
a massa. Esta "faz a obra de arte mergulhar em si, envolve-a com o ritmo de suas vagas, absorve-as em seu fluxo" ${ }^{28}$. Adorno cogita sobre a realização afetiva através do objeto de arte quando cria o conceito de Leidenschaft zum Antasten (paixão pelo palpável). Dessa forma ele opõe a contemplação o fato de que o objeto de arte desperta a necessidade tátil. ${ }^{29}$

Benjamim diferencia a percepção tátil (o hábito) da percepção ótica (o recolhimento). Como exemplo disso, Benjamim comenta sobre a arquitetura. Nela a arte está presente não no lugar da contemplação, do distanciamento, mas do hábito, do morador que percebe sua própria casa com olhos costumeiros, ou o habitante da cidade que todos os dias se depara com as mesmas obras arquitetônicas. A recepção tátil se faz pelo uso, e a ótica pela contemplação. Ambas não se correspondem, mas no caso da arquitetura, a recepção tátil se sobressai e determina a própria contemplação, representação consciente da obra ${ }^{30}$. Essa percepção gradual, que acontece casualmente e se torna hábito está presente também na linguagem cinematográfica.

Como, então, esse estado de distração pode preparar o indivíduo para um comportamento crítico diante da obra? Isso se faz justamente pela predisposição ao choque que o hábito proporciona. Não apenas por isso, mas também porque o hábito se contrapõe a percepção da lógica formal, tendo, portanto, uma potencialidade revolucionária. Benjamim vê no cinema essa possibilidade como uma linguagem propiciadora dessa experiência. O autor afirma sobre o cinema:

(...) cujo valor de distração é fundamentalmente de ordem tátil, isto é, baseia-se na mudança de lugares e ângulos, que golpeiam intermitentemente 0 espectador. Compare-se a tela em que se projeta 0 filme com a tela em que se encontra o quadro. Na primeira a imagem se move, mas na segunda não. Esta convida o espectador á contemplação; diante dela, ele pode abandonar-se às suas associações. Diante do filme isso não é mais possível. Mas o espectador percebe uma imagem, ela não é mais a mesma. Ela não pode ser fixada, nem como o quadro nem como algo real. ${ }^{31}$

${ }^{28}$ BENJAMIM, Walter. "A Obra de Arte na Era de sua Reprodutibilidade Técnica" in:_Magia e Técnica, Arte e Política - Obras Escolhidas I, Tradução: Sérgio Paulo Rouanet. São Paulo: Brasiliense, 2008, p. 193.

${ }^{29}$ ADORNO, Theodor W. Teoria Estética. Tradução: Artur Mourão. Lisboa: Edições 70, 2008, p. 36.

${ }^{30}$ BENJAMIM, Walter. "A Obra de Arte na Era de sua Reprodutibilidade Técnica" in: Magia e Técnica, Arte e Política - Obras Escolhidas I, Tradução: Sérgio Paulo Rouanet. São Paulo: Brasiliense, 2008, p. 193.

${ }^{31}$ Id. Ibid., p. 192. 
Como se percebe no pensamento de Benjamim, o grande contraponto da distração está justamente nessa relação dialética entre o hábito e o choque. $O$ filme reproduz o movimento das massas, das cidades, o movimento frenético dos citadinos, o fluxo contínuo dos carros e transeuntes. A percepção desse tipo de gente que se desenvolveu na era burguesa não se adéqua e nem deseja mais se adequar às antigas linguagens artísticas. Ela deseja o novo.

A nova percepção, essa de tipo moderno, se dá pelo hábito. Este é o rompimento com a lógica de dedução, do sentido fixo do conceito. O conceito de Freud dos chocs, em seus estudos sobre o sonho, embasa o pensamento de Benjamim. A reflexão é a defesa dos chocs, ou seja, dos estímulos. Ao refletir a mente fixa um acontecimento num determinado lugar temporal. Quando acontece o espanto é porque houve a falha da recepção desse estímulo. Ou seja, compreendese no trecho supracitado, que a linguagem cinematográfica golpeia o individuo com suas sequências de imagens, e no movimento constante as mentes se distraem e ao mesmo tempo são surpreendidascom o corte da fixação lógica dos acontecimentos. Acreditando que o choque advindo dos elementos artísticos do cinema pode produzir uma descarga de energia para o despertar, Benjamin cita os filmes de Chaplin:

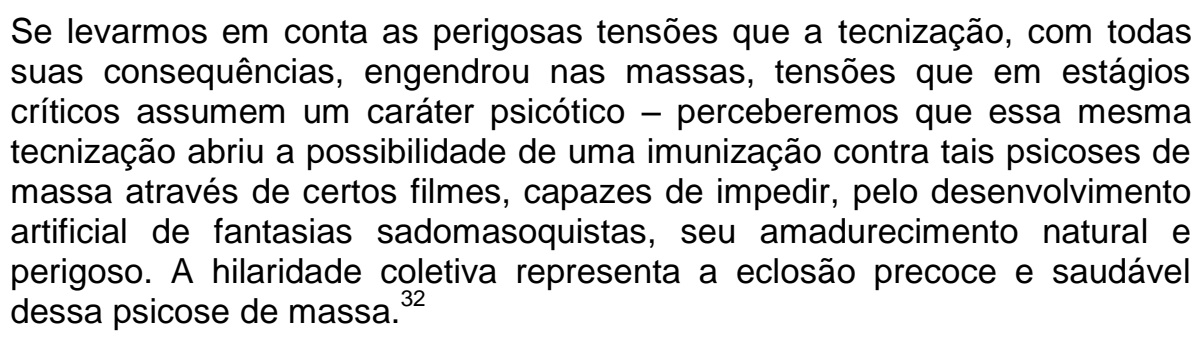

O mesmo aconteceu nos movimentos artísticos do início do século $X X, 0$ dadaísmo e o surrealismo. Movimentos que buscam essa barbárie moderna. São movimentos que tentam desumanizar a arte, ressecá-la de qualquer comoção, ou parâmetro estético vigente. O absurdo e a distração casam-se como um tapa seco no rosto da moral burguesa. O surrealismo, principalmente, deseja revelar, de forma tão maquinal que se torna espontânea, uma necessidade interior. Ele deseja mostrar o segredo, trazer à superfície o inconsciente. Por isso o vidro pode tomar um sentido para além do mencionado no capítulo anterior:

\footnotetext{
${ }^{32}$ BENJAMIN, "A Obra de arte na era de sua reprodutibilidade técnica" in: Magia e Técnica, Arte e Política - Obras Escolhidas I.Tradução: Sergio Paulo Rouanet. São Paulo: Brasiliense, 2010, p.190.
} 
Viver numa casa de vidro é uma virtude revolucionária por excelência. (...) um exibicionismo moral que nos é necessário. A discrição no que diz respeito á própria existência, antes uma virtude aristocrática, transforma-se cada vez mais num atributo de pequenos burgueses arrivistas. ${ }^{33}$

Percebe-se, portanto, que para Benjamim o moderno contém em si uma ambiguidade melancólica, restando ao homem a responsabilidade de decidir-se, de tomar uma atitude. Essa modernidade é sempre bárbara, consigo mesma, com a cultura que edificou para Iheservir de alicerce. Benjamim considera a situação onde a modernidade colocou o homem,dramática e conflituosa, mas ao mesmo tempo ele alerta para a possibilidade de despertar o potencial do homem com o próprio trauma, com o choque que a vida na fantasmagoria da metrópole carrega em si, para tirar o homem da areia movediça da cultura. Uma arte que deseja essa revolução precisa daquilo que a consome: o novo.

Adorno e Benjamim vêem no novo a utopia necessária da arte e, no entanto, uma situação tensa e problemática que ela carrega nos tempos modernos. Benjamim leva isso para o âmbito político assim como Adorno, mas este traz a questão da forma estética como o impactante potencial crítico. Adorno não acredita que a distração tenha potencial crítico, pois considera que a distração pressupõe o aniquilamento da força expressiva da obra, tendo em vista que não há como distrair alguém apresentando um conteúdo de difícil acesso, hermético. Portanto, a obra para incomodar politicamente os indivíduos precisa expressar sua tensão em uma forma estética hermética.

As imagens estéticas encontram-se sujeitas à proibição das imagens. Sob este aspecto, a aparência estética e, além disso, a sua consequência última na obra de arte hermética, é justamente a verdade. As obras herméticas afirmam o que lhes é transcendente não como ser numa esfera superior, mas realçam, mediante a sua impotência e superfluidade no mundo empírico, também o momento da fragilidade no seu conteúdo. ${ }^{34}$

Ela proíbe as imagens por não desejar uma linguagem criptografada, pois o momento mimético da obra não se faz na cópia da realidade, mas em fazer aparecer uma realidade segunda que se faz nas bases empíricas. Por consequência a obra é fechada, pois não deseja uma identificação simples, justamente por não ser copia

\footnotetext{
${ }^{33}$ BENJAMIN, Walter. "O Surrealismo. O último instantâneo da inteligência europeia" in: Magia e Técnica, Arte e Política - Obras Escolhidas I.Tradução: Sergio Paulo Rouanet. São Paulo: Brasiliense, 2010, p. 24.

${ }^{34}$ ADORNO, Theodor W. Teoria Estética. Tradução: Artur Mourão. Lisboa: Edições 70, 2008, p. 163.
} 
fiel, pois ao instigar o sujeito ela provoca a angustia da inconformação com o padrão burguês social e estético. É por isso que sua verdade é frágil, uma vez que ela não passa de aparência. A linguagem da aparência estética, a ilusão que a arte provoca aponta a ilusão da mercadoria, mas também denuncia a ratio burguesa alicerçada na ciência e nos conceitos lógicos tradicionais.

Benjamim recorre à questão do moderno e da pobreza criadora que o novo pode trazer à obra, pois não se trata de proteger a arte da evolução técnica, mas de canalizar essas forças brutas da experiência miserável da modernidade como uma impactante revolução política. É o que diz o autor:

Antes desses videntes e interpretes de sinais, ninguém havia percebido de que modo a miséria, não somente a social como a arquitetônica, a miséria dos interiores, das coisas escravizadas e escravizantes, transformam-se em niilismo revolucionário. ${ }^{35}$

\section{À guisa de conclusão}

Sendo assim, o que resta à arte? Separar-se por completo da humanidade, enjaular-se na cultura de vidro? Ou usar essa frieza vítrea como força revolucionária? Ou mais, quebrar de uma vez por todas as paredes esterilizadas com a qual a cultura tenta revesti-la em favor do seu progresso? Todos esses questionamentos, discutidos ao longo do artigo, apresentam perspectivas distintas nos pensamentos de ambos os autores. O que se pode perceber é que os caminhos diferentes tomados nas teorias aqui discutidas convergem para uma resposta dramática, mas não necessariamente escatológica.

Como criação do homem, a arte também sofre, é o seu destino sofrer, pelo seu caráter imanente ao homem. Não há espaço para uma forma de arte que não se importa com a condição miserável desses últimos séculos. Uma obra de arte hoje precisa tirar do seu próprio sofrimento a revanche contra o sistema que a sufoca. Isso não é garantia de triunfo. Muito provavelmente, por nutrir-se desses antagonismos, não deseje um modo humano único e politicamente harmonizado. A obra de arte, seja em Benjamim ou em Adorno, tem o dever de chacoalhar as estruturas sociais, estéticas, econômicas, subjetivas. O homem é o grande sujeito de

\footnotetext{
${ }^{35}$ BENJAMIN, Walter."O Surrealismo. O último instantâneo da inteligência europeia".In: Magia e Técnica, Arte e Política- Obras Escolhidas I. Tradução: Sergio Paulo Rouanet. São Paulo: Brasiliense, 2010, p. 25.
} 
todo esse terremoto que ela pretende causar na sutileza de sua forma. Pois é no homem onde o maior de todos os abalos acontece primeiro: a angústia.

Talvez o logos da cultura moderna tente a todo custo afastar o homem de suas próprias obras. Mas a arte, por seu principio ilusório, tem a capacidade de ludibriar essas mesmas forças que tentam a todo custo ressecá-la e fragilizá-la. Sua grande mentira: sua forma frágil, quase imperceptível, pode causar uma hecatombe em um sujeito sentado numa sala de teatro, ou quem sabe, em seu quarto, num domingo banal, lendo uma obra literária. A sua força lançada a quem possa experimentá-la nunca é em vão.

Pode-se pensar com isso, que a grande revolução da arte está no homem, ainda nele. E que apesar da corda bamba em que ele passeia balance incessantemente acima do abismo, ainda sim é um fio de possibilidade. Muito provavelmente a revolução das obras não seja a da massa unida em favor de um ideal, mas a dos indivíduos conscientes de sua condição, como seres políticos, e portanto, sofredores irreconciliáveis com o mundo. Um dia tudo isso pode, quem sabe, reverberar de maneira espacialmente maior. Para tanto, é preciso que a arte e os artistas tomem consciência do seu dever, ou melhor, da sua condição inalienável: o caráter político e crítico da obra de arte. Enquanto isso é preciso ruminar constantemente esses questionamentos, pensar sobre suas possibilidades e trazer novas perspectivas que possibilitem ao homem e à cultura uma construção mais consciente das suas próprias fragilidades, a ponto de torná-las espontâneas, inconscientes, como pensa Benjamin. Assim, a autocrítica e o desenvolvimento da arte, do pensamento e da cultura nunca cessará. 


\section{REFERÊNCIAS}

ADORNO, Theodor W. Teoria Estética, Tradução de Artur Mourão, Lisboa: Edições 70, 2008.

Palavras e Sinais - modelos críticos 2. Tradução de Maria Helena Ruschel, Petrópolis: Vozes, 1995.

e HORKHEIMER, Max. Dialética do Esclarecimento, Tradução de Guido Antônio de Almeida, Rio de Janeiro: Jorge Zahar Editor, 2006.

BENJAMIN, Walter. Magia e Técnica, Arte e Política. Obras Escolhidas I. Tradução de Sérgio Paulo Rouanet, São Paulo: Brasiliense, 1985.

Humanitas-UFMG, 2006.

Passagens. Tradução de WilliBolle et Alii, Belo Horizonte:

Origem do Drama Barroco Alemão. Tradução: Sergio Paulo Rouanet,São Paulo, Editora Brasiliense, 1984. 